\title{
Minute Times Gram Per Milliliter Per Kilogram
}

National Cancer Institute

\section{Source}

National Cancer Institute. Minute Times Gram Per Milliliter Per Kilogram. NCI Thesaurus.

Code C112337.

Minutes times grams per milliliter, divided by kilograms. 